\title{
DOSSIER
}

\section{Ejércitos y repúblicas en el mundo hispanoamericano}

Tras una larga ausencia en los debates historiográficos predominantes en Hispanoamérica, durante las últimas dos décadas la cuestión del papel jugado por la guerra y lo militar en la configuración de las sociedades modernas ha experimentado un verdadero revival. Resulta impresionante, cuando se lo contrasta con el período anterior, la cantidad de coloquios, simposios, dossiers, tesis, libros, e incluso revistas científicas enteras que se consagran ahora al estudio de un tema que había sido tenido como marginal para la historia científica. Podríamos especular largo y tendido sobre los motivos detrás de tan abrupto cambio de actitud por parte de los historiadores y sus lectores: ¿Se debe simplemente a la vocación de llenar un vacío historiográfico? ¿Guarda relación con las posibilidades intelectuales abiertas por el fin del ominoso tutelaje que los ejércitos mantuvieron sobre nuestros países a lo largo del siglo XX? ¿Forma parte de una curiosidad más general despertada por las vertiginosas mutaciones que experimentan hoy en día la guerra y los asuntos militares? Como sea, debemos reconocer que nos encontramos ante un campo de estudio que se halla en plena expansión a la vez que comienza a acumular un recorrido considerable. Y como sucede habitualmente en nuestra disciplina, cuando un nuevo campo va ganando densidad, comienzan a vislumbrarse con mayor claridad, por encima de la proliferación monográfica, grandes temas o problemas que dan a las discusiones un cierto horizonte común.

Uno de esos grandes ejes orientadores está constituido, sin duda, por la cuestión de la relación entre la guerra y las formas republicanas de gobierno. En este punto los latinoamericanos no estamos solos, porque el tema ocupa también un lugar central en historiografías como la anglosajona, la francesa o la italiana ${ }^{1}$. El mundo iberoamericano resulta lo suficiente-

1 Una buena muestra en Pierre Serna, Antonino de Francesco y Judith A. Miller (eds.), Republics at War, 1776-1840. Revolutions, Conflicts, and Geopolitics in Europe and the Atlantic World, (New York: Palgrave Macmillan, 2013). 
mente amplio, sin embargo, para que podamos distinguir determinados matices que lo caracterizan y que merecen una atención particular. Por ejemplo, respecto del problema crucial de la temporalidad relevante para el análisis: ¿Cuándo empieza y cuándo termina, en efecto, el proceso de reformulación de la cuestión militar en clave republicana?

En un esclarecedor ensayo reciente, la historiadora Hilda Sábato plantea que lo esencial de lo que llama el "experimento republicano" ocurrió, en Latinoamérica, a lo largo del medio siglo que transcurre entre 1820 y $1870^{2}$. Este marco temporal, sin duda adecuado cuando la cuestión es pensada desde la historia política, ¿resulta suficiente cuando los historiadores pensamos el problema desde la historia de la guerra? Como vemos en los artículos que componen este dossier, la respuesta es probablemente negativa, ya que a los autores se les hace indispensable retroceder por lo menos hasta la convulsionada década revolucionaria de 1810, o prolongar el análisis hasta la implementación de los ejércitos nacionales de servicio militar obligatorio, recién a fines del siglo XIX. De este modo, si privilegiamos como objeto de estudio a la evolución de las formas de la guerra y de la organización militar, el "momento" republicano se entiende mejor no ya como una unidad contenida en sí misma, sino como una fase dentro de un movimiento más amplio.

Considero que la manera más productiva de encuadrar el problema es pensar, para toda Hispanoamérica, en un extenso ciclo de reformas militares y movilizaciones armadas que se extiende desde las décadas de $1760 \mathrm{y}$ 1770 -con el inicio de las principales reformas del aparato militar español tras los descalabros de la Guerra de los Siete Años- hasta la consolidación definitiva de los ejércitos nacionales, ocurrida en la mayoría de los países entre las décadas de 1880 y 1890. Lo que podríamos llamar, para nuestra región, "el largo siglo de la guerra". ¿Cuáles son, desde nuestra perspectiva, las características principales de este período? Por un lado, estamos ante un evidente proceso de "militarización" de la sociedad: empezando con las reformas borbónicas, con un nivel máximo durante las guerras revolucionarias y con reincidencias periódicas gracias a los conflictos ci-

2 Hilda Sábato, Republics of the New World. The Revolutionary Political Experiment in Nineteenth-Century Latin America. Princeton: Princeton University Press, 2018. 
viles e internacionales del siglo XIX, lo que tenemos es un incremento notable de la proporción de la población masculina y adulta que sirvió en las fuerzas de guerra (tanto de línea como milicianas), lo que acarreó profundas consecuencias económicas y políticas (entre ellas el acaparamiento de los cargos ejecutivos de gobierno por parte de los jefes militares). Por otro lado, esta militarización alimentó (y fue forzada por) una muy intensa actividad guerrera que podemos mensurar tanto en la frecuencia como en la magnitud de los conflictos bélicos, campañas y combates que poblaron la historia hispanoamericana, en particular entre la década de 1810 y las grandes guerras internacionales de la Triple Alianza (1864-1870) y del Pacífico (1879-1883), lo que contrasta fuertemente con la menor incidencia de guerras sufridas por la región en el período colonial o durante el siglo XX. Por último, y esto es lo que nos interesa principalmente en este dossier, tanto la militarización como la mayor actividad guerrera tuvieron lugar en el marco de un profundo y conflictivo proceso de reformulación de la relación entre los pueblos y sus fuerzas militares, o si se quiere, entre la sociedad y la guerra.

En efecto, a lo largo de este largo siglo de la guerra una de las principales cuestiones que está en juego es precisamente la de quién tiene el derecho o la obligación de portar armas, para formar unidades militares de qué tipo y que respondan a cuál gobierno. Pensado así, buena parte de la agitada y variopinta vida político-militar del continente podría reducirse a una dinámica muy simple: los núcleos estatales centrales (primero la Corona y, tras el estallido revolucionario, sus sucesores nacionales) intentaron adquirir lo que, en términos weberianos, podríamos llamar el monopolio del uso legítimo de la fuerza, subordinando a las milicias y fortaleciendo a un ejército de línea o regular disciplinado, pero fueron resistidos una y otra vez por cuerpos locales (los cabildos, los pueblos, las provincias) que intentaron resguardar sus antiguas prerrogativas milicianas y su autonomía de acción, hasta capitular exhaustos, recién sobre fines del siglo XIX.

Es dentro de este ciclo que la experiencia republicana cobra un sentido militar. La experimentación con las formas de la soberanía popular permitió aunar los nuevos principios políticos en boga (representación, ciudadanía, derechos del hombre) con las viejas disputas medievales entre las ciudades y la Corona respecto de las obligaciones militares de cada uno, reavivan- 
do y dando nuevos sentidos a una lucha secular. A partir de la ruptura revolucionaria, esta combinación resultó efectivamente explosiva, ya que dotó a cada provincia - e incluso a cada pueblo- con una fuerza militar propia, de muy bajo costo y una capacidad operativa nada desdeñable. El "ciudadano soldado" que emergió en este contexto como agente principal de la política y la guerra hispanoamericana, tomaba las armas para proteger a su pueblo de cualquier amenaza externa, pero también, de manera significativa, para defender y ejercer su libertad política frente a cualquier abuso cometido por los infaltables tiranos de turno. Mientras este modelo predominó - digamos de nuevo, con Hilda Sabáto, entre 1820 y 1870-, va de suyo que la inestabilidad política y la fragmentación del poder estuvieron a la orden del día en casi todo el territorio. Recién con el cierre del laboratorio republicano, y con la consecuente consolidación definitiva de los Estados nacionales y sus ejércitos de línea se logró pacificar, al menos en términos relativos, a la región. El aprendizaje realizado durante la fase anterior, sin embargo, no desaparecería de un momento a otro, y seguiría alimentando tanto las tendencias autoritarias de los militares como los afanes revolucionarios de los civiles, dando a la vida política el carácter convulsionado que signó buena parte del siglo XX.

El presente dossier ofrece un rico muestrario de las diversas vías de acceso que la nueva historia de la guerra ha encontrado para estudiar el problema de lo militar y la república en nuestra región, al mismo tiempo que manifiesta las coincidencias de fondo que se van perfilando en el campo. Como el lector podrá apreciar, los trabajos aquí reunidos, más allá de su multiplicidad de enfoques, rondan en torno a dos grandes temas que se insertan directamente dentro de la dinámica general esbozada en las páginas que anteceden. El primero está dado por la necesidad, a partir de las revoluciones, de ampliar las bases de reclutamiento para las fuerzas de guerra, recurriendo a segmentos de la población previamente exentos del servicio militar. El segundo, de manera complementaria, versa sobre los esfuerzos estatales por generar una institucionalidad capaz de contener y canalizar a las enormes fuerzas militares así creadas.

En un continente social y racialmente muy diverso como el americano, en efecto, la posibilidad de armar a la población de origen africano (y en especial a la esclavatura) o a los indígenas constituyó desde un principio, tanto 
para los revolucionarios como para los realistas, un dificultoso dilema en el que debían sopesarse cuidadosamente las ventajas militares con los peligros para el orden social. El fantasma de los sucesos de Santo Domingo acechaba por cierto a las élites gobernantes, pero la tentación de recurrir a todos los recursos disponibles era muy alta en algunas regiones con baja densidad de población. En su artículo sobre los negros, pardos y morenos de una de las principales fuerzas permanentes del Río de la Plata ${ }^{3}$, Alejandro Morea muestra muy bien que los mismos jefes del ejército estaban divididos al respecto. Mientras que algunos se resistían al reclutamiento de castas basados en prejuicios morales y raciales, o por un simple respeto al derecho de propiedad de los dueños de esclavos; otros, como José de San Martín, consideraban que solo con el reclutamiento masivo de los esclavos negros se salvaría la revolución, ya que estos constituían la tropa más disciplinada que pudiera pedirse.

Otra opción disponible para ampliar el reclutamiento era el recurso a la población extranjera, ya sea que se tratase de mercenarios, de voluntarios o de inmigrantes. Con el fin de la guerra revolucionaria en Europa, como es sabido, quedó desocupada una gran cantidad de mano de obra militar altamente calificada, desde los rangos más bajos hasta los más altos del escalafón. La oficialidad napoleónica, en particular, sería muy requerida por las nuevas repúblicas, dispuestas a pagar un precio considerable por unos servicios que se ofrecían a veces al mejor postor. Patrick Puigmal -sin duda el principal especialista del tema para nuestra región- logró, en un monumental diccionario ${ }^{4}$, identificar con nombre y apellido a casi dos mil de ellos que actuaron en Hispanoamérica. Su pasado al servicio del Imperio, su origen geográfico y sus ideales liberales y republicanos no dejarían de despertar suspicacias entre los americanos y tensiones con los gobiernos de turno. De hecho, en el artículo ${ }^{5}$ que forma parte de este dossier, Puigmal señala que un porcentaje considerable de estos oficiales resultó enjuiciado y perseguido a causa de su participación en la agitada vida po-

3 Morea, Alejandro. "Negros, pardos y morenos en el Ejército Auxiliar del Perú (1810-1820)", Historia Caribe Vol. XIV No. 35 (Julio-Diciembre 2019): 25-54. DOI: http://dx.doi.org/10.15648/ hc.35.2019.2

4 Patrick Puigmal, Diccionario de los militares napoleónicos durante la independencia de América Latina, 3 vols. (Santiago de Chile: Centro de Investigaciones Diego Barros Arana, 2013-2019).

5 Puigmal, Patrick Jacques. "Militares y militantes políticos: el actuar de los napoleónicos en la construcción republicana en América latina durante la independencia (1810-1835)", Historia Caribe, Vol. XIV No. 35 (Julio-Diciembre 2019): 55-83. DOI: http://dx.doi.org/10.15648/hc.35.2019.3 
lítica local. Un número nada desdeñable de ellos terminó, inclusive, en el cadalso. Al mismo tiempo, como lo demuestra abundantemente el autor, es indudable que una vez finalizada la guerra muchos de estos hombres se comprometieron con la mejora de las capacidades estatales y de la calidad republicana de la vida política local, ya sea en funciones administrativas y de gobierno, en la prensa y en la educación o, muy comúnmente, en la instrucción de los nuevos cuadros de los ejércitos nacionales nacientes.

Ahora bien, el papel de los extranjeros como factor militar no se agotaría con los napoleónicos ni con la guerra revolucionaria. Por el contrario, las décadas siguientes, marcadas a fuego por guerras civiles, configuraron un caldo de cultivo en donde los inmigrantes y residentes extranjeros tendrían un actuar bélico destacado bajo formas híbridas y novedosas. En un agudo análisis, Mario Etchechury Barrera despliega a modo de ejemplo uno de estos casos: el de las milicias de voluntarios franceses en un puerto tan cosmopolita como el de Montevideo. El artículo ${ }^{6}$ muestra, de manera convincente, que las famosas "legiones" conformadas por extranjeros harían mucho más que proteger los intereses materiales de algunos comerciantes en un contexto inestable. Lejos de la neutralidad política que les asignaba el derecho de gentes, estos milicianos voluntarios participarían activamente de las luchas republicanas locales, ejerciendo de hecho una "ciudadanía de ultramar" y defendiendo valores que entendían a partir de posicionamientos globales, muchas veces disonantes de los adoptados por sus respectivas legaciones diplomáticas.

A esta ampliación -por momentos espontánea y desbordante- de la población militarmente activa correspondió siempre, aunque con éxito muy diverso, un intento sostenido de los gobiernos de turno por subordinar e institucionalizar a las fuerzas de guerra resultantes. En este proceso, que duró décadas, los Estados nacientes intentaron imponer formas de organización militar consecuentes con las normas y ordenanzas provenientes de Europa, para chocar una y otra vez con la falta de recursos y la incompatibilidad de las tradiciones militares locales.

$6 \quad$ Etchechury Barrera, Mario. "Las milicias de voluntarios franceses en el Río de la Plata. Tradiciones bélicas, politización y diplomacia informal en tiempos de crisis (1829-1851)”, Historia Caribe, Vol. XIV No. 35 (Julio-Diciembre 2019): pp.85-118 DOI: http://dx.doi.org/10.15648/hc.35.2019.4 
La Nueva Granada fue probablemente el país de la región que más esfuerzos hizo, a la salida de la guerra revolucionaria, por regularizar sus fuerzas militares y dar a los militares veteranos una transición ordenada hacia el futuro republicano, como lo demuestran sus ambiciosos planes de premios y entregas de tierras para aquellos combatientes que eran dados de baja. En un artículo ${ }^{7}$ extraordinariamente bien documentado, Angie Guerrero Zamora estudia otra faceta crucial de este accionar, cual es la conformación de un sistema de montepío capaz de asistir a las viudas y madres de los oficiales caídos en acción. El análisis de las solicitudes de pensión, donde se destaca la perspectiva de género, nos ofrece una perspectiva invaluable de la manera en que el naciente Estado republicano se relacionaba con sus ciudadanos. Los límites, sin embargo, están bien presentes incluso en Nueva Granada: los recursos disponibles no son suficientes, las pensiones cubren solo a los familiares de oficiales, el éxito de las solicitudes suele estar sujeto a la calidad de las relaciones de la interesada y en definitiva, la institución no sobrevive sino de manera intermitente a la merced de los cambios de gobierno.

Una lectura similar emerge del trabajo ${ }^{8}$ de Luis Ervin Prado Arellano, referido a las provincias del Cauca en las décadas de 1830 a 1850. En un contexto de capacidades estatales bastante limitadas, los militares de la región eran llamados a cumplir toda una serie de funciones que excedían a su finalidad guerrera específica: tareas de policía, mantenimiento del orden y control social, cuando no directamente el ejercicio del gobierno en vastas regiones. El problema es que, más allá de la voluntad política de contar con ejércitos profesionales capaces de hacerles frente (como lo expresaba la Constitución neogranadina de 1832), la realidad de los maltrechos erarios locales imponía la búsqueda de alternativas menos onerosas. Casi toda Hispanoamérica adoptó entonces una fórmula bien arraigada en sus tradiciones coloniales: mantener un efectivo de línea muy reducido y sostenerse, más bien, en nutridas milicias, llamadas luego Guardias Nacio-

$7 \quad$ Guerrero Zamora, Angie. "El amparo a las viudas de militares en el sistema pensional republicano (1820-1860)", Historia Caribe, Vol. XIV No. 35 (Julio-Diciembre 2019): pp.119-147 DOI: http:// dx.doi.org/10.15648/hc.35.2019.5

8 Prado Arellano, Luis Ervin."Desplegando el Estado: los ejércitos republicanos en las provincias del Cauca, 1832-1855”, Historia Caribe, Vol. XIV No. 35 (Julio-Diciembre 2019): pp.149-178 DOI: http://dx.doi.org/10.15648/hc.35.2019.6 
nales. Eran pues los guardias nacionales del Cauca (es decir, los mismos habitantes de la región) quienes debían custodiar el correo y los caudales o luchar contra la plantación ilegal de tabaco, la producción clandestina de aguardiente o el contrabando de mercancías. Las tensiones y contradicciones surgidas de semejante estrategia no son difíciles de imaginar.

La distancia entre lo expresado en los decretos gubernamentales y la práctica concreta en el terreno podía ser, en muchos casos, abismal. A lo largo de todo el continente, los bellos discursos sobre los "ejércitos virtuosos" de "ciudadanos soldados" chocaban una y otra vez con la falta de voluntarios para el servicio y la sorda negativa de los paisanos cada vez que eran llamados a incorporarse a las fuerzas regulares. La realidad, pues, es que la mayoría de la tropa de línea estaba siempre constituida por hombres destinados a servir por la fuerza, ya sea por haber cometido un delito (siendo así "condenados" a purgar su pena en el ejército) o, más simplemente, por haber sido considerados "vagos y malentretenidos" (lo que de hecho constituía una criminalización del modo de vida de algunos sectores populares). Esta dura cara de la militarización republicana emerge con gran claridad en el artículo9 que Lucas Codesido le dedica al caso rioplatense en las décadas de 1860 a 1880, donde queda demostrado que, en plena fase de consolidación estatal y nacional, lo que seguimos encontrando son las viejas prácticas del contingente que hacían de los ejércitos reales en América verdaderas prisiones ambulantes donde la deserción estaba a la orden del día.

Este carácter de "presos soldados" se cortaría recién, en la mayoría de los países, sobre el filo del cambio de siglo con la aplicación de las leyes de "Servicio Militar Obligatorio". Sin embargo, David Víctor Velásquez Silva, que dedica su artículo ${ }^{10}$ al estudio del caso peruano (la Ley del Servicio Militar Obligatorio data allí de 1898), nos disuade de pensar, como suele hacerlo la historiografía del período, en un antes y un después rotundo

9 Codesido Marzoratti, Lucas. "Los Soldados, Sus Jefes Y El Estado: La Construcción De La Obediencia En El Ejército De Línea (Argentina, 1862-1882)", Historia Caribe, Vol. XIV No. 35 (Julio-Diciembre 2019): pp.179-211 DOI: http://dx.doi.org/10.15648/hc.35.2019.7

10 Velásquez Silva, David Víctor. "La reforma de la conscripción en el Perú en el tránsito del siglo XIX al XX. La aplicación de la Ley del Servicio Militar Obligatorio de 1898”, Historia Caribe, Vol. XIV No. 35 (Julio-Diciembre 2019): pp.213-246 DOI: DOI: http://dx.doi.org/10.15648/hc.35.2019.8 
a partir de la sanción de este tipo de iniciativas. Si los variados esfuerzos de modernización y profesionalización de las fuerzas, que datan de los años 1870, comenzaban ahora a rendir frutos más visibles y consistentes, la aplicación de la conscripción universal no se logró de inmediato ni solucionó todos los problemas decimonónicos de la noche a la mañana. Por el contrario, la existencia de milicias locales siguió teniendo ardientes defensores, la igualdad ante el reclutamiento despertó resquemores sociales y raciales en los sectores acomodados, buena parte del procedimiento recayó en autoridades locales poco comprometidas con la reforma y que debían enfrentar la resistencia de la población rural e indígena. Es con el correr de los años que, pese a todo, el Estado fue logrando sus objetivos, desarrollando capacidades burocráticas y una presencia territorial más eficiente. El fenómeno de la guerra seguiría muy presente en la vida de la sociedad peruana y en la de varios otros países de la región, pero los problemas propios de su etapa experimental republicana irían quedando atrás y serían reemplazados por otros.

\section{Alejandro Rabinovich \\ Editor Invitado \\ Consejo Nacional de Investigaciones Científicas y Técnicas - CO- NICET (Argentina) \\ Universidad Nacional de la Pampa (Argentina)}

\section{Luis Ervin Prado Arellano}

Editor Invitado

Universidad del Cauca (Colombia)

\section{Jorge Conde Calderón}

Editor Invitado

Universidad del Atlántico (Colombia)

DOI: http://dx.doi.org/10.15648/hc.35.2019.1 